\title{
Potential dental effects of infants' fruit drinks studied in vitro
}

\author{
BY T. H. GRENBY, M. MISTRY AND T. DESAI \\ Department of Oral Medicine \& Pathology, United Medical \& Dental Schools, Guy's Hospital, \\ London SE1 9RT
}

(Received 23 October $1989-$ Accepted 19 January 1990)

\begin{abstract}
Eighteen different infants' drinks from five manufacturers were examined for their carbohydrate, calcium, phosphorus and acid contents, and their attack on tooth mineral. Seven of the drinks were compared with nine varieties of adults' soft drinks, and demineralization was studied with and without the presence of a cariogenic oral streptococcus. The influence of the acids already in the drinks in dissolving $\mathrm{Ca}$ and $\mathrm{P}$ outstripped that of any acid generated in these studies in vitro by microbial fermentation of the sugars they contained, giving an indication of their relative erosiveness rather than their cariogenic action. Various other features of the drinks relevant to dental health were identified. Titratable acid was a better guide than $\mathrm{pH}$ to their dental properties. Although there were considerable differences between the various infants' drinks, taken as a group, their acidity levels and demineralizing powers were generally lower than those of the adults' drinks.
\end{abstract}

Infants' drinks : Dental erosion: Dental caries

There is growing concern over dietary factors that can affect the health of the dentition very early in life, including long-term sweetened medicaments and fruit drinks that are specially formulated for children and also adults' fruit drinks sometimes given to children. Attention has recently been drawn to the properties of infants' drinks in the literature (Asher \& Read, 1987; Kelly \& Bruerd, 1987; Silver, 1987; Smith \& Shaw, 1987; Curzon et al. 1988), and by disparaging comments in the media. A few case reports hinting at links between the consumption of infants' fruit drinks and dental erosion (Asher \& Read, 1987; Smith \& Shaw, 1987) or caries (Kelly \& Bruerd, 1987; Silver, 1987) have appeared, but very little research has been done specifically on the properties of these drinks, and constructive information is lacking on a number of important questions:

(A) With a wide range of products of various flavours now available from several different manufacturers, what is known of their composition, e.g. acidity and content of sugars?

(B) What is their effect on the tooth mineral? Is this relevant to the processes of dental erosion or caries, or both?

(C) Do they show any superiority over adults' soft drinks used for the same purpose in infant feeding?

(D) Taking account of the choice of flavours and combinations of fruit juices in the drinks, and whether or not they require dilution before use, can any guidance be given on which of them offer the best prospects for dental health?

A two-part laboratory research project was undertaken to investigate these questions by methods based on those used in a recent evaluation of the properties of a range of adults' soft drinks (Grenby et al. 1989).

Expt 1. Concentrating on questions A, B and D, an examination was made of the properties of a range of infants' drinks on the market in 1986-7, including information on their carbohydrate, calcium and phosphorus concentrations, all of which have a bearing on their dental effects. Comparative studies were made of their influence on demineralizing the 
chief inorganic component of enamel (hydroxylapatite), by measuring the action of the intrinsic acids already in the drinks and any additional acid generated by the fermentation of the sugars in the drinks by human dental plaque micro-organisms. These were singleexposure studies focusing on erosiveness rather than cariogenicity, which depends on repeated exposure of specific sites on the teeth under the dental plaque to localized acid production from the frequent intake of sugar-containing food and drinks.

Expt. 2. To fulfil objective C, similar demineralization studies on hydroxylapatite (a) in the absence of any micro-organisms, and (b) in the presence of a known cariogenic strain of oral streptococcus were made with both infants' and adults' drinks.

\section{MATERIALS AND METHODS}

Drinks

Expt 1. A total of eighteen different kinds of infants' drinks were tested in the first experiment (see Table 1, p. 276).

Expt 2. In the second experiment the properties of a selection of the infants' drinks were compared with those of a range of adults' drinks (see Table. 3, p. 278), the dental effects of which had already been evaluated in vitro (Grenby et al. 1989).

\section{Expt 1. Methods of examination of the drinks}

Basic information. This was compiled from the manufacturers' descriptions of the drinks, their ingredients including any added carbohydrate, subjective grading of sweetness on a $0-10$ scale $(0$, zero sweetness; 10 , excessively sweet $)$ by a panel of twelve adults, and average cost per serving.

Acidity levels. These were recorded as $\mathrm{pH}$ values and as $\mathrm{ml} 0.05 \mathrm{M}$-sodium hydroxide required to neutralize by titration $1.00 \mathrm{ml}$ of the juices in ready-to-drink form (titratable acid).

Carbohydrate concentrations. These were determined by analysis or adduced from information supplied by the manufacturers. Total carbohydrate was estimated by the phenol/sulphuric acid absorptiometric method (Dubois et al. 1956); glucose by the glucose oxidase (EC 1.1.3.4) absorptiometric method (Boehringer Mannheim); and fructose by colorimetry (Kulka, 1956).

$\mathrm{Ca}$ and $\mathrm{P}$ concentrations. $\mathrm{Ca}$ was estimated by atomic absorption spectroscopy; $\mathrm{P}$ by the molybdate-absorptiometric method of Allen (1940).

The demineralization potential. This was determined by gently agitating $10.00 \mathrm{ml}$ of the drinks, diluted as directed, with $0.010 \mathrm{~g}$ hydroxylapatite (Biorad) at $37^{\circ}$, withdrawing samples at 2, 4, 6 and $24 \mathrm{~h}$, centrifuging at $3000 \mathrm{rev} / \mathrm{min}$ to remove any solid particles, and analysing the supernatant liquid for $\mathrm{Ca}$ and $\mathrm{P}$ entering solution by the analytical methods given previously.

Acid production and demineralization in the presence of oral micro-organisms. These were measured after incubating $\left(37^{\circ}\right) 5.00 \mathrm{ml}$ of the drinks $+5.00 \mathrm{ml}$ sterile peptone-P liquid medium (zero carbohydrate, low P) with $0.2 \mathrm{ml}$ of a pooled suspension of human interstitial dental plaque micro-organisms from a panel of volunteers (Grenby \& Phillips, 1989), withdrawing samples at set intervals and determining the $\mathrm{pH}$, total titratable acid, $\mathrm{Ca}$ and $\mathrm{P}$ as described previously.

\section{Expt. 2. Comparison of adults' and infants' drinks}

Simultaneous demineralization studies. These were conducted as described previously, exposing $0.010 \mathrm{~g}$ hydroxylapatite to $10.00 \mathrm{ml}$ of the drinks at $37^{\circ}$, but the length of contact was reduced to 30 and $60 \mathrm{~min}$. Ca and $\mathrm{P}$ entering solution were recorded after the subtraction of the $\mathrm{Ca}$ and $\mathrm{P}$ supplied by the drinks themselves. 
Demineralization in the presence of cariogenic oral micro-organisms. This was measured as described previously, except that the inoculum was a standardized liquid culture of Streptococcus mutans NCTC 10449 (a known cariogenic organism) instead of a plaque suspension. Samples were taken for $\mathrm{Ca}$ and $\mathrm{P}$ analyses after gentle agitation at $37^{\circ}$ for 1 , 5,16 and $24 \mathrm{~h}$. 'Blank' measurements were made in the absence of any micro-organisms. The amounts of $\mathrm{Ca}$ and $\mathrm{P}$ already present in the drinks were subtracted from the final values.

\section{Statistical analysis}

All the experiments were replicated four times to permit statistical analysis of the results by Student's $t$ test, the $F$ test or Wilcoxon's sum of ranks test, as appropriate.

\section{RESULTS \\ Expt 1}

Basic information. The eighteen different types of drinks examined in the first part of the work are described in Table 1. Under 'ingredients relevant to dental health' are listed carbohydrate sources and acids that could have a role in demineralizing enamel (apart from those carbohydrates and acids supplied by the natural fruit juices themselves).

Total carbohydrate, glucose and fructose. Concentrations in the drinks are summarized in Table 2. The values apply to batches of the drinks on the market in 1986-7, but some of the formulations may have been changed since then. Examining them in ready-to-drink form, types 5-9 and 13-15, which did not require dilution before use, had lower carbohydrate levels than all the other types that had to be diluted. Types 5-9 also had lower glucose contents, whereas it was types $1-4$ that were the lowest in fructose. The types to be used neat, without dilution, had appreciably higher $\mathrm{Ca}$ and $\mathrm{P}$ contents than any of the others.

Acidity values. These are shown in Fig. 1. The $\mathrm{pH}$ values were all in the range of 2.9.4.6, with thirteen of the eighteen drinks between $3 \cdot 0$ and $4 \cdot 0$. Low $\mathrm{pH}$ values did not correlate well with high total acidity levels as determined by titration, which gave a more sensitive guide to the enamel-demineralizing capacity of the drinks. There was considerable variation in the total titratable acid even among the range of products of a single manufacturer, but in general the types to be used neat (types 5-9 and 13-15) tended to show higher values than those requiring dilution, with the exception of type 18 .

The effects of the drinks in demineralizing hydroxylapatite. Findings under standard conditions are shown in Fig. 2. The extent of attack was particularly low with types 14 and 15 , both of which were high in $\mathrm{Ca}$ and $\mathrm{P}$ (Table 2), and also with types 7 and 13 (the $\mathrm{Ca}$ and $\mathbf{P}$ contents of type 7 were the highest of all).

Experiments in the presence of oral micro-organisms. There was hardly any change in the acidity (measured by $\mathrm{pH}$ and titratable acid) of media containing the infants' drinks on incubation with cultures of plaque bacteria after 2, 4, 6 and $24 \mathrm{~h}$. Consequently the amounts of $\mathrm{Ca}$ and $\mathrm{P}$ dissolving from hydroxylapatite under the influence of this acid were very low compared with the demineralization by the drinks themselves in the absence of any oral bacteria (Fig. 2). The Ca values ranged from 0 to $42 \mu \mathrm{g} / \mathrm{ml}$ and $\mathrm{P}$ from 4 to $15 \mu \mathrm{g} / \mathrm{ml}$, with types 10-15 giving slightly higher values than the rest.

\section{Expt 2. Comparison of adults' and infants' drinks}

Measurements of the acidity and $\mathrm{Ca}$ and $\mathrm{P}$ contents of the sixteen different drinks are given in Table 3. Comparing the nine adults' and seven infants' drinks, the $\mathrm{pH}$ values were significantly higher $(P<0.001)$ and the titratable acid levels significantly lower $(P<0.05)$ in the infants' formulations. Among the adults' drinks, types 20 and 24 (lemon juice and 


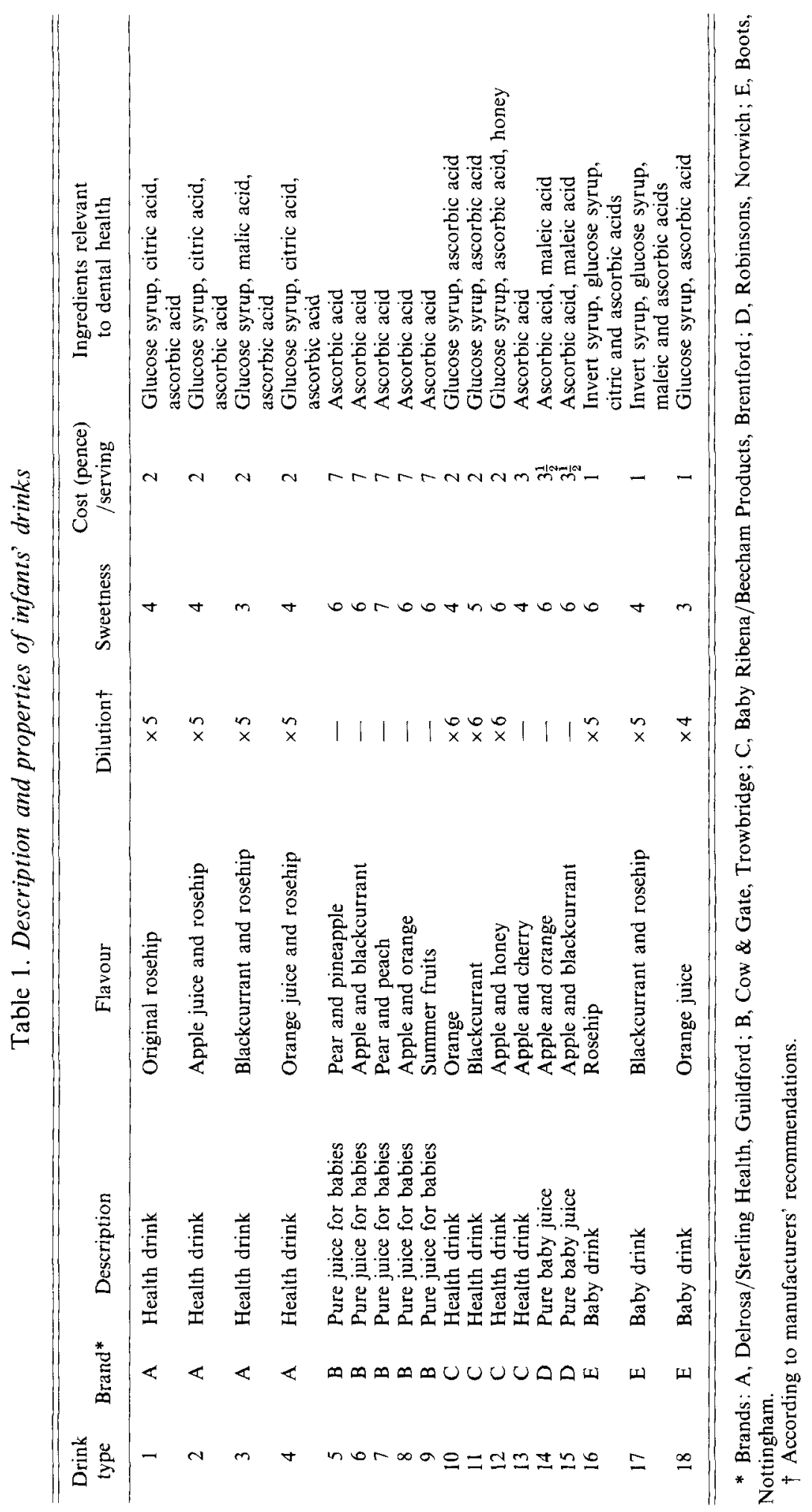


INFANTS' FRUIT DRINKS: DENTAL EFFECTS

Table 2. Carbohydrate, calcium and phosphorus contents of infants' drinks

\begin{tabular}{cccccc}
\hline $\begin{array}{c}\text { Drink } \\
\text { type }\end{array}$ & $\begin{array}{c}\text { Total carbohydrate } \\
(\mathrm{g} / \mathrm{l})\end{array}$ & $\begin{array}{c}\text { Glucose } \\
(\mathrm{g} / \mathrm{l})\end{array}$ & $\begin{array}{c}\text { Fructose } \\
(\mathrm{g} / \mathrm{l})\end{array}$ & $\begin{array}{c}\text { Calcium } \\
(\mathrm{mg} / \mathrm{l})\end{array}$ & $\begin{array}{c}\text { Phosphorus } \\
(\mathrm{mg} / \mathrm{l})\end{array}$ \\
\hline $1 \dagger$ & 162 & 68 & 2 & $21 \cdot 3$ & $24 \cdot 0$ \\
$2 \dagger$ & 156 & 68 & 3 & $20 \cdot 9$ & $20 \cdot 0$ \\
$3 \dagger$ & 152 & 74 & 2 & $24 \cdot 9$ & $20 \cdot 0$ \\
$4 \dagger$ & 170 & 78 & 3 & $24 \cdot 1$ & $24 \cdot 0$ \\
5 & 86 & 30 & 50 & $164 \cdot 4$ & $67 \cdot 0$ \\
6 & 86 & 27 & 56 & $157 \cdot 5$ & $87 \cdot 0$ \\
7 & 102 & 40 & 56 & $173 \cdot 1$ & $100 \cdot 0$ \\
8 & 94 & 36 & 54 & $121 \cdot 3$ & $80 \cdot 0$ \\
9 & 88 & 36 & 49 & $149 \cdot 4$ & $94 \cdot 0$ \\
$10^{\dagger}$ & 168 & 80 & 28 & $19 \cdot 1$ & $32 \cdot 8$ \\
$11 \dagger$ & 140 & 80 & 27 & $18 \cdot 4$ & $16 \cdot 7$ \\
$11^{\dagger}$ & 195 & 100 & 34 & $14 \cdot 6$ & $10 \cdot 0$ \\
13 & 70 & 50 & ND & $99 \cdot 4$ & $33 \cdot 5$ \\
14 & 115 & 50 & ND & $162 \cdot 5$ & $73 \cdot 5$ \\
15 & 115 & 50 & ND & $170 \cdot 6$ & $80 \cdot 0$ \\
$16 \dagger$ & 166 & 50 & 32 & $24 \cdot 6$ & $6 \cdot 7$ \\
$17 \dagger$ & 150 & 50 & 29 & $22 \cdot 5$ & $9 \cdot 0$ \\
$18 \dagger$ & 140 & 110 & 12 & $45 \cdot 2$ & $95 \cdot 0$ \\
\hline
\end{tabular}

ND, not determined.

* For details see Table 1 .

$\uparrow$ Diluted according to the manufacturers' recommendations.

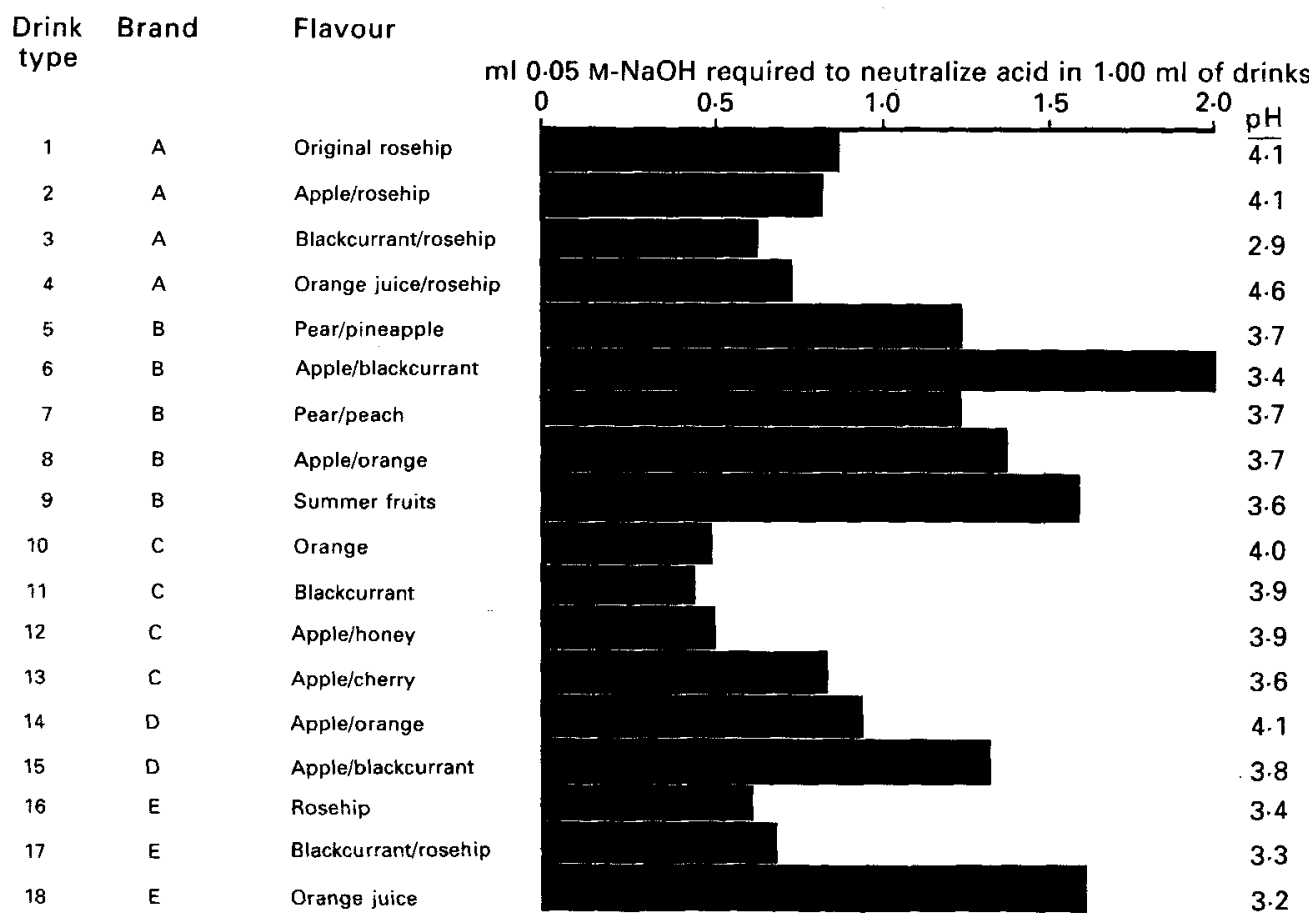

Fig. 1. Infants' fruit drinks: titratable acid and pH. Drinks diluted as recommended. For details of brand/manufacturer, see Table 1. 


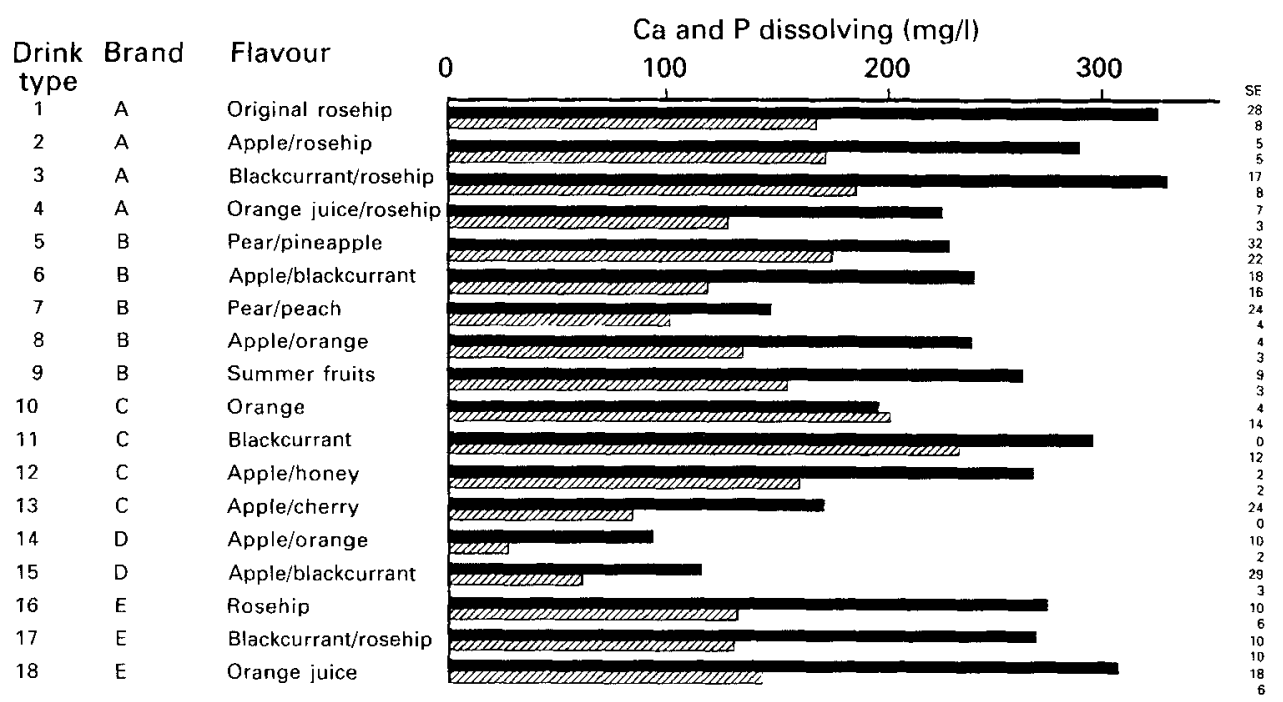

Fig. 2. Calcium ( $\mathbf{D})$ and phosphorus (团) released from hydroxylapatite by demineralization in infants' fruit drinks, after subtraction of $\mathrm{Ca}$ and $\mathrm{P}$ supplied by the drinks. Values are given as means with their standard errors for four replicates. For details of brand/manufacturer, see Table 1.

Table 3. Acid, calcium and phosphorus contents of adults' and infants' drinks

\begin{tabular}{|c|c|c|c|c|c|}
\hline $\begin{array}{l}\text { Drink } \\
\text { type }\end{array}$ & Flavour & $\mathrm{pH}$ & $\begin{array}{c}\text { Titratable acid } \\
(\equiv \mathrm{ml} 0.05 \mathrm{M}- \\
\text { sodium hydroxide) }\end{array}$ & $\begin{array}{l}\text { Calcium } \\
(\mathrm{mg} / \mathrm{l})\end{array}$ & $\begin{array}{c}\text { Phosphorus } \\
(\mathrm{mg} / \mathrm{l})\end{array}$ \\
\hline \multicolumn{6}{|c|}{ Adults' drinks } \\
\hline 19 & Low-sugar orange* & $3 \cdot 34$ & $0 \cdot 76$ & 41 & 0 \\
\hline 20 & Lemon juice drink* & $2 \cdot 49$ & $3 \cdot 12$ & 37 & 9 \\
\hline 21 & Orange drink* & 2.64 & 0.97 & 34 & 6 \\
\hline 22 & Blackcurrant* & $2 \cdot 89$ & $0 \cdot 83$ & 36 & 11 \\
\hline 23 & Pure apple juice & $3 \cdot 29$ & 1.88 & 73 & 2 \\
\hline 24 & Pure orange juice & $3 \cdot 56$ & 3.01 & 130 & 101 \\
\hline 25 & Cola drink & $2 \cdot 48$ & $1 \cdot 29$ & 82 & 159 \\
\hline 26 & Diet lemonade & $2 \cdot 87$ & 1.96 & 2 & 0 \\
\hline 27 & Lime-juice cordial* & $2 \cdot 57$ & 1.95 & 40 & 0 \\
\hline \multicolumn{6}{|c|}{ Infants' drinks $\dagger$} \\
\hline \multirow[t]{2}{*}{1} & Brand A & & & & \\
\hline & Original rosehip* & 4.07 & 0.83 & 32 & 15 \\
\hline \multirow[t]{2}{*}{2} & Brand A & & & & \\
\hline & Apple and rosehip* & $4 \cdot 13$ & 0.76 & 40 & 9 \\
\hline \multirow[t]{2}{*}{6} & Brand $\mathrm{B}$ & & & & \\
\hline & Apple and blackcurrant & $3 \cdot 33$ & $1 \cdot 86$ & 113 & 75 \\
\hline \multirow[t]{2}{*}{7} & Brand $\mathrm{B}$ & & & & \\
\hline & Pear and peach & 3.74 & 1.04 & 116 & 71 \\
\hline \multirow[t]{2}{*}{11} & Brand $\mathrm{C}$ & & & & \\
\hline & Blackcurrant* & $3 \cdot 91$ & 0.54 & 39 & 10 \\
\hline \multirow[t]{2}{*}{12} & Brand C & & & & \\
\hline & Apple and honey* & 3.79 & 0.54 & 30 & 6 \\
\hline \multirow[t]{2}{*}{16} & Brand $E$ & & & & \\
\hline & Rosehip* & $3 \cdot 32$ & 0.64 & 36 & 5 \\
\hline
\end{tabular}

* Diluted $\times 5$.

† For details see Table 1 . 


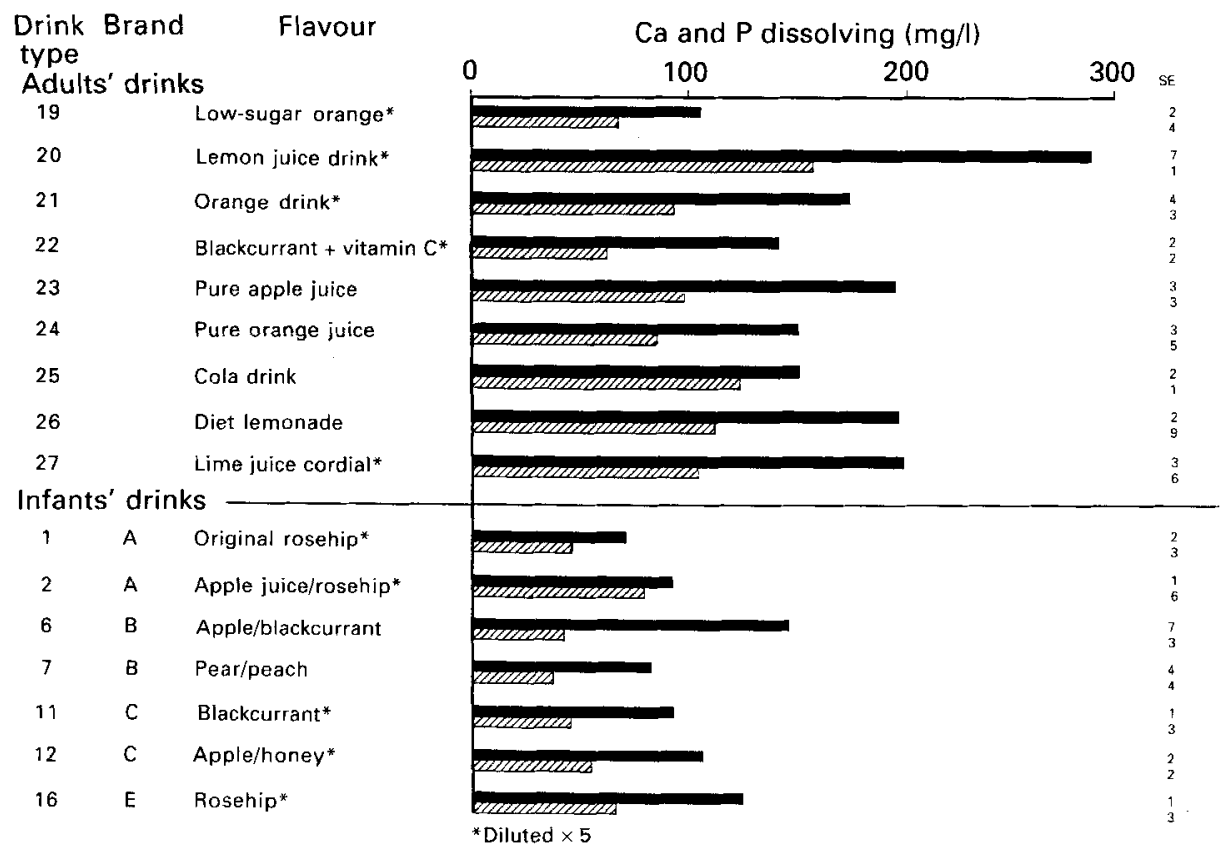

Fig. 3. Comparison of adults' and infants' drinks: demineralization of hydroxylapatite in 30 min. No microorganisms were present. Calcium ( $\square$ ) and phosphorus $(\square)$ released, after subtraction of $\mathrm{Ca}$ and $\mathrm{P}$ supplied by the drinks. Values are means with their standard errors for four replicates.

orange juice) had particularly high levels of titratable acid. Of the infants' drinks type 6 had the highest acid content. Pure orange juice was relatively rich in $\mathrm{Ca}$, and the carbonated cola had by far the highest $\mathrm{P}$ level.

The results of the demineralization studies $(30 \mathrm{~min}$ exposure of hydroxylapatite to the drinks in the absence of micro-organisms) are shown in Fig. 3, after subtraction of the amounts of $\mathrm{Ca}$ and $\mathrm{P}$ contained in the drinks themselves. The greatest demineralization was brought about by the lemon juice health drink, but among the other adult drinks that gave relatively high values in the early stages were pure apple juice, lime juice cordial and the two carbonated drinks. Differences between the infants' drinks were less well-defined, except that types 6 and 16 tended to show higher values than the rest. The main point, however, was the comparison of the adults' $v$. the infants' drinks. Combined into two groups of nine and seven respectively, the differences in $\mathrm{Ca}$ and $\mathrm{P}$ dissolving were highly significant, with the adults' drinks giving higher values than the infants' drinks $(\mathrm{Ca}, P<0.005$; $\mathrm{P}$, $P<0.002$ ). The pattern of results was similar when the exposure time was increased to $1 \mathrm{~h}$, except that the quantities of $\mathrm{Ca}$ and $\mathrm{P}$ dissolving were greater, and the differences between the adults' and infants' drinks became less distinct.

In the incubation experiments in the presence of oral micro-organisms, $\mathrm{Ca}$ and $\mathrm{P}$ analyses were carried out at intervals over $24 \mathrm{~h}$, but $5 \mathrm{~h}$, towards the end of the period of logarithmic growth, was used for observing the demineralizing action of the acids formed by the micro-organisms from the carbohydrates in the drinks. The results, again after subtraction of the $\mathrm{Ca}$ and $\mathrm{P}$ supplied by the drinks, are shown in Fig. 4. There was wide variation in the effects of the nine different adults' drinks. The highest demineralization values were recorded in the presence of lemon juice drink, pure orange and apple juices and lime juice cordial, but at the other end of the scale the two carbonated drinks gave the 


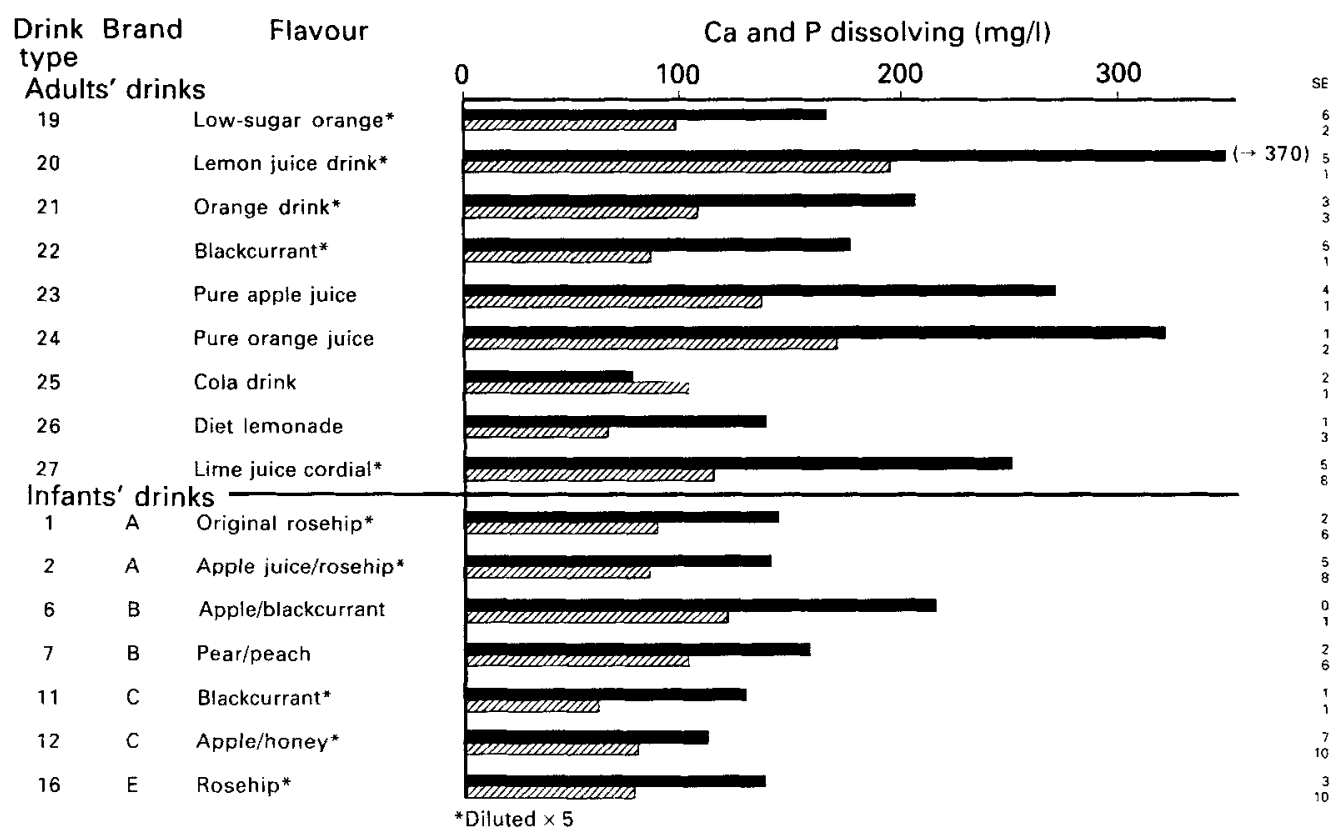

Fig. 4. Comparison of adults' and infants' drinks in incubations at $37^{\circ}$ for $5 \mathrm{~h}$ with Streptococus mutans NCTC 10449. Values are means with their standard errors for four replicates.

lowest values. Values for the infants' drinks were more uniform, with the highest $\mathrm{Ca}$ and $P$ values from type 6 , but there was no statistically significant difference between the adults' and infants' drinks in dissolving either $\mathrm{Ca}$ or $\mathrm{P}$.

\section{DISCUSSION}

The four basic questions posed initially are discussed here.

(A) Table 1 summarizes some of the main features of a range of infants' fruit drinks, and shows the organic acids and carbohydrate materials that could have a bearing on the dental properties of the drinks. Citric, malic and maleic acids occur in eight of the eighteen varieties of drinks. Their possible demineralizing effects in adults' soft drinks in relation to their $p K_{\mathrm{a}}$ values have already been discussed (Grenby et al. 1989), but another acid that has not been fully investigated from this angle is ascorbic acid (vitamin $\mathrm{C}$ ), which was listed as present in varying amounts in all the infants' drinks. This has $p K_{a}$ values of $4 \cdot 10$ and 11.79 at $16-24^{\circ}$, and the first of these is certainly low enough to play a part in the demineralization process.

The measurements of acidity in Fig. 1 show the greater sensitivity of the titratable acid determinations compared with the $\mathrm{pH}$ values. The components of the titratable acid have been studied in detail by Iwami et al. (1989). It can be seen from Fig. 1 that most of the drinks not requiring dilution (types 5-9 and 13-15) contained more free acid than the others, with the exception of type 18. There is some dispute over the concept of a 'critical $\mathrm{pH}$ ' below which acid from the microbial fermentation of foods and drinks becomes injurious to the teeth, but all the pH values quoted in Fig. 1 fall well below the usually accepted critical levels.

The commonest added carbohydrate material was glucose syrup (in ten of the eighteen 
drinks). Used in the form of solutions such as these drinks, this is believed to have better dental properties than sucrose (Grenby \& Leer, 1974), but the degree of fermentation to acid that it undergoes by the action of oral bacteria depends on its composition: a grade of glucose syrup rich in low-molecular-weight saccharides such as glucose and maltose is likely to be more readily converted to acids than one containing less glucose and a higher proportion of oligosaccharides. Drinks types 12,16 and 17 also contained honey or invert syrup, the main sugar components of which are undoubtedly easily fermentable by acidogenic oral bacteria.

Some values for carbohydrate concentrations in the drinks are given in Table 2 . In readyto-drink form, total carbohydrate $(\mathrm{g} / \mathrm{l})$ was higher in those that required dilution (range 140-195) than in those to be used neat (range 86-115). Glucose levels (g/l) also tended to be higher in the drinks requiring dilution (range 50-110, compared with 27-50 for the undiluted types). Fructose contents were variable, but the average was below $30 \mathrm{~g} / \mathrm{l}$ and the highest only $56 \mathrm{~g} / \mathrm{l}$, helping to correct the misconception that fructose is the main sugar in fruit juices. Sucrose was not estimated, but some values for a different selection of baby drinks have been reported elsewhere (Curzon et al. 1988). One problem in analysing for sucrose is that it can be hydrolysed to its constituent monosaccharides under the prevailing acidic conditions in fruit juices, so that sucrose values for samples that have been stored for varying lengths of time may not give a reliable guide to their cariogenic potential. All three sugars, sucrose, glucose and fructose, are fermentable to acid by a variety of oral microorganisms.

The drinks not requiring dilution before use (types 5-9 and 13-15) were far richer in Ca and $P$ than the others (Table 2). The significance of this depends on the form in which they exist in the drinks, but there is a belief that high local concentrations of $\mathrm{Ca}$ and $\mathrm{P}$ may help to limit demineralization of the teeth (Lilienthal, 1977), and fortification of ice-lollies with $\mathrm{Ca}$ and $\mathrm{P}$ substantially improved their dental properties (Wagg et al. 1965; Grenby \& Saldanha, 1981).

(B) What are the effects of the drinks on tooth mineral? The variation in demineralizing power between eighteen different varieties of the drinks can be seen in Fig. 2. There was no correlation evident between these values and the acidity measurements of the drinks (Fig. 1), but it is interesting to note that the drinks which dissolved least hydroxylapatite, types 14 and 15 followed by types 7 and 13 , were among the richest in $\mathrm{Ca}$ and $\mathrm{P}$ (Table 2). All the drinks that contained rosehip were associated with comparatively high demineralization, but it is not known if this was related to the ascorbic acid level of the rosehip juice or to its other components.

In the presence of oral micro-organisms, acid production in the course of incubation, and consequently $\mathrm{Ca}$ and $\mathrm{P}$ dissolving under its influence, were very low, suggesting that the acidity of the drinks was sufficient to curb the growth of the micro-organisms, and that under the conditions of these studies the potential dental effects of the acids already present in the fruit juices appear to outweigh those of any microbially-produced acid from the sugars in the drinks. This was also found to hold true in earlier studies with a range of adults' soft drinks (Grenby et al. 1989).

The implication is that an important concern with these infants' drinks should be their erosiveness rather than their cariogenicity, but of course it must be borne in mind that as they all contain sugars, no matter whether natural or added, if they are allowed to reside in the mouth over long periods as part of a frequent, protracted sugar intake pattern, it is likely that they will be able to contribute to the caries process, in which sugars serve as a substrate for acid formation.

(C) In view of these properties of the infants' drinks, it has been questioned whether they serve any useful purpose at all, and whether they have any special virtues for children 
compared with ordinary adults' soft drinks. This issue does not seem to have been examined before, but it formed a major part of the research reported here, with the results summarized in Table 3 and Figs. 3 and 4.

Although acidity levels in the infants' drinks as a group were significantly lower than those of the adults' drinks, there was wide variation among the infants' drinks, and the highest titratable acid levels were well above some of the lower ones of the adults' drinks. This was reflected in the demineralization findings (Fig. 3), although the infants' drinks on the whole showed better dental properties than the adults' drinks. It is obvious that some of the adults' drinks, such as the lemon juice health drink and the carbonated drinks, would not normally be given to very young children, but if the other adults' pure juices and concentrates without additives were diluted sufficiently and used with proper care, it is difficult to see why they should be any less suitable for young children than the specially designated infants' drinks.

Incubations in the presence of a cariogenic oral micro-organism, Streptococcus mutans, showed a different picture (Fig. 4), with no significant differences between the infants' and adults' drinks, owing to the wide variation in demineralization among the adults' drinks. The findings for $\mathrm{Ca}$ and $\mathrm{P}$ dissolving shown in Fig. 4 include the effects on hydroxylapatite of both the acids already present in the drinks and the acid generated by microbial fermentation of the sugars in the drinks. By comparing Fig. 4 with Fig. 3 it can be seen that the greater part of the demineralization shown in Fig. 4 was brought about by the constituent acids rather than the microbially-produced acid, even though Fig. 4 records changes over a $5 \mathrm{~h}$ period as against only $30 \mathrm{~min}$ for Fig. 3. In fact it is likely that if demineralization experiments in the absence of any bacteria had been continued for as long as $5 \mathrm{~h}$ the values for $\mathrm{Ca}$ and $\mathrm{P}$ dissolving would approach very closely those in Fig. 4 . This is supported by the findings of earlier studies with adults' soft drinks (Grenby et al. 1989), and it may indicate an inability of oral micro-organisms (Streptococcus mutans in this case) to grow well and retain their metabolic activity under the acidic conditions in the drinks. A similar inhibitory effect has been shown with levels of $1.00 \%$ of citric or malic acids in sweets (Grenby \& Saldanha, 1989). Preservatives such as benzoate and metabisulphite in adults' drinks may also have a suppressing role, but they should not be present in the infants' drinks, in which ascorbic acid has an antioxidant function.

One unexplained anomaly is that more $\mathrm{Ca}$ and $\mathrm{P}$ appeared to dissolve under the influence of the two carbonated drinks, types 25 and 26, when no micro-organisms were present (Fig. 3 ), than in the incubations with Streptococcus mutans. In the case of the cola it could be postulated that its high concentrations of $\mathrm{Ca}$ and especially $\mathrm{P}$ (see Table 3) might help to counteract the process of demineralization, but this would not apply with the carbonated lemonade.

(D) Finally, it is very difficult to lay down any guidelines on which drinks are safest for the teeth. New varieties appearing on the market may have different properties from those that have been tested. As can be seen from the list of products examined, many different fruit juices are used, and these can vary in composition depending on such factors as source and dilution. Earlier work with adults' drinks showed that citrus juices could be especially erosive (Grenby et al. 1989), but dilution and the presence of other ingredients may modify their effects; for example, Fig. 2 shows formulations containing orange juice with both high and low demineralizing activity (types 18 and 14).

Of course the flavour of the drink is chosen by the adult who buys it. Adults also decide if it is to be diluted before use and if it should be made more palatable by adding sugar. In spite of pleas from the health-care professions that infants' drinks between meals should consist only of unsweetened milk or water, these fruit drinks will continue to be used, so the manufacturers' main concerns should be to produce formulations that are as safe as 
possible, and to give clear directions for risk-free use plus warnings on possible misuse, an area in which there have been inadequacies, and in which improvements in labelling are still needed.

From what is known of the properties of infants' fruit drinks and what has been found in the present work, it would make good sense to keep acid and fermentable carbohydrate levels as low as possible, to reconsider the amount of ascorbic acid needed, and perhaps to give further attention to $\mathrm{Ca}$ and $\mathrm{P}$ contents.

\section{REFERENCES}

Allen, R. J. L. (1940). The estimation of phosphorus. Biochemical Journal 34, 858-864.

Asher, C. \& Read, M. J. F. (1987). Early enamel erosion in children associated with the excessive consumption of citric acid. British Dental Journal 162, 384-387.

Curzon, M. E. J, Alemi, Z. \& Duggal, M. S. (1988). Sugars in baby and infants' drinks. Lancet i, p. 539.

Dubois, M., Gilles, K. A., Hamilton, J. K., Rebers, P. A. \& Smith, F. (1956). Colorimetric method for the determination of sugars and related substances. Analytical Chemistry 28, 350-356.

Grenby, T. H. \& Leer, C. J. (1974). Reduction in 'smooth-surface' caries and fat accumulation in rats when sucrose in the drinking-water is replaced by glucose syrup. Caries Research 8, 368-372.

Grenby, T. H. \& Phillips, A. (1989). Studies of the dental properties of lactitol compared with five other bulk sweeteners in vitro. Caries Research 23, 315-319.

Grenby, T. H., Phillips, A., Desai, T. \& Mistry, M. (1989). Laboratory studies of the dental properties of soft drinks. British Journal of Nutrition 62, 451-464.

Grenby, T. H. \& Saldanha, M. G. (1981). Inhibitors against the erosion of enamel mineral by ice-lollies: tests in vitro. Journal of Dental Research 60, 1136, Abstr. 234.

Grenby, T. H. \& Saldanha, M. G. (1989). Comparison of Lycasin versus sucrose sweets in demineralisation studies of human enamel and hydroxylapatite. Caries Research 22, 269-275.

Iwami, Y., Hata, S., Takahashi, N. \& Yamada, T. (1989). Difference in amounts between titratable acid and total carboxylic acids produced by oral streptococci during sugar metabolism. Journal of Dental Research 68, 16-19.

Kelly, M. \& Bruerd, B. (1987). The prevalence of baby bottle tooth decay among two native American populations. Journat of Public Health Dentistry 47, 9497.

Kulka, R. G. (1956). Colorimetric estimation of ketopentoses and ketohexoses. Biochemical Journal 63, 542-548.

Lilienthal, B. (1977). Phosphates and Dental Caries. Basel: Karger.

Silver, D. H. (1987). A longitudinal study of infant feeding practice, diet and caries, related to social class in children aged 3 and 8-10 years. British Dental Journal 163, 296-300.

Smith, A. J. \& Shaw, L. (1987). Baby fruit juices and tooth erosion. British Dental Journal 162, 65-67.

Wagg, B. J., Friend, J. V. \& Smith, G. S. (1965). Inhibition of the erosive properties of water ices by the addition of calcium and phosphorus. British Dental Journal 119, 118-123. 